\title{
Nutrient Uptake and Organic Acid Anion Metabolism in Lupins and Peas Supplied with Nitrate
}

\author{
S. P. LOSS , A. D. ROBSON and G.S.P. RITCHIE
}

\begin{abstract}
Unlike many plants reported in the literature, lupins do not excrete $\mathrm{OH}^{-}$in amounts equivalent to the net excess of inorganic anion uptake over inorganic cation uptake. To investigate the mechanisms involved in the maintenance of charge balance, nutrient uptake and organic anion accumulation of lupins and peas supplied with a range of $\mathrm{NO}_{3}^{-}$ concentrations, were compared.

Lupins absorbed less $\mathrm{NO}_{3}^{-}$than peas on a dry weight basis, which largely accounted for the smaller excess of anion uptake over cation uptake in lupins than in peas at the same $\mathrm{NO}_{3}^{-}$supply. When anion uptake exceeded cation uptake, peas excreted an equivalent charge of $\mathrm{OH}^{-}$, whereas lupins excreted much smaller amounts of $\mathrm{OH}^{-}$than the excess of anion over cation uptake. It was calculated that lupins excreted significant amounts of organic anions when anion uptake exceeded cation uptake, whereas organic anion excretion from peas was negligible, regardless of their $\mathrm{NO}_{3}^{-}$ supply and cation-anion balance.

In this study, organic anion excretion was measured from lupin roots grown in near-sterile conditions while supplied with $\mathrm{NO}_{3}^{-}$at 0,500 and $2000 \mu \mathrm{M}$. Although complete sterility was not achieved, there was close agreement between the organic anion excreted and the excess anion over cation uptake.
\end{abstract}

\section{INTRODUCTION}

Unlike most plants (Van Beusichem, 1981; Jarvis and Robson, 1983; Van Beusichem, Kirkby and Baas, 1988), nodulated lupins (Lupinus angustifolius $\mathbf{L}$.) grown in solution culture did not excrete $\mathrm{OH}^{-}$when supplied with $\mathrm{NO}_{3}^{-}$(Loss, Robson and Ritchie, 1993b). When $\mathrm{NO}_{3}^{-}$was supplied to the lupins at $750 \mu \mathrm{M}$, inorganic cation-anion uptake was balanced but $\mathrm{H}^{+}$excretion continued to occur, and when $\mathrm{NO}_{3}^{-}$was supplied at $5000 \mu \mathrm{M}$, inorganic anion uptake exceeded inorganic cation uptake and the $\mathrm{pH}$ of the nutrient solution was unaffected. Similar results were obtained by Atwell (1992), who found that the $\mathrm{pH}$ of the nutrient solution did not increase when lupins were supplied with $\mathrm{NO}_{3}^{-}$.

To explain these results, we proposed that lupins maintain their internal charge balance by excreting organic acid anions rather than $\mathrm{OH}^{-}$in exchange for the uptake of inorganic anions (Loss et al., 1993 b). Malate and citrate are the organic anions present in the largest quantities in lupins and their $\mathrm{pKa}$ values are low enough not to affect the external $\mathrm{pH}$ of the growing medium at $\mathrm{pH} 6.0$. The excretion of $\mathrm{H}^{+}$coupled to cation uptake and the reduction of $\mathrm{NO}_{3}^{-}$ and $\mathrm{SO}_{4}^{--}$within plants produces $\mathrm{OH}^{-}$and any rise in cellular $\mathrm{pH}$ is prevented by the synthesis of organic acids (Davies, 1973). Greater organic anion accumulation has been measured in castor oil plants (Ricinus communis L.) supplied with $\mathrm{NO}_{3}^{-}$than in those supplied with $\mathrm{NH}_{4}^{+}$(Van Beusichem et al., 1988). Unlike many plants, including peas (Pisum sativum L.), the reduction of $\mathrm{NO}_{3}^{-}$is mainly confined to the roots of lupins when supplied with $5 \mathrm{mM} \mathrm{NO}_{3}^{-}$or less, and it is only at high $\mathrm{NO}_{3}^{-}$supplies $(10 \mathrm{~mm}$ ) that significant quantities are reduced in the shoots (Andrews et al., 1984). This could indicate a difference in the mechanisms of charge balance.

The aim of this study was to investigate nutrient uptake and organic anion metabolism in lupins and peas supplied with a range of $\mathrm{NO}_{3}^{-}$concentrations.

\section{MATERIALS AND METHODS}

\section{Experiment $I$}

Experimental design. The aim of this experiment was to compare nutrient uptake and organic anion accumulation in unnodulated peas and lupins supplied with $\mathrm{NO}_{3}^{-}$, with the hypothesis that peas absorb more $\mathrm{NO}_{3}^{-}$and accumulate more organic anions than lupins. The effects of four concentrations of $\mathrm{NO}_{3}^{-}(250,750,2500,5000 \mu \mathrm{M})$ on nutrient uptake, cation-anion balance, $\mathrm{H}^{+} / \mathrm{OH}^{-}$excretion and organic anion accumulation in the roots and shoots of unnodulated lupin and pea seedlings were examined. The experiment included three replicates and was conducted in root cooling tanks at $20^{\circ} \mathrm{C}$, in an air-conditioned glasshouse during Sep. and Oct. 1990, when internal air temperatures varied between 15 and $25^{\circ} \mathrm{C}$.

Seedling preparation. Seeds of L. angustifolus cv. Yandee and $P$. sativum L. cv. Dundale were sterilised with a $1 \%$ 
solution of $\mathrm{NaOCl}$ to prevent any contamination with rhizobia. The seeds were then germinated on a stainless steel screen suspended on the surface of an aerated solution of $10^{-4} \mathrm{M} \mathrm{CaSO}_{4}$ and $10^{-6} \mathrm{M} \mathrm{H}_{3} \mathrm{BO}_{3}$. After $7 \mathrm{~d}$, seedlings were transfered to an aerated, nutrient solution at a density of eight seedlings per 5.01 pot. The nutrient solution contained the following concentrations of nutrients $(\mu \mathrm{M}): \mathrm{CaSO}_{4}, 625$; $\mathrm{K}_{2} \mathrm{SO}_{4}, 600 ; \mathrm{MgSO}_{4}, 200 ; \mathrm{NaH}_{2} \mathrm{PO}_{4}, 30 ; \mathrm{H}_{3} \mathrm{BO}_{3}, 5$; FeNaEDTA, $3 ; \mathrm{MnSO}_{4}, 1.0 ; \mathrm{ZnSO}_{4}, 0.75 ; \mathrm{CuSO}_{4}, 0.2$; $\mathrm{CoSO}_{4}, 0 \cdot 2 ; \mathrm{Na}_{2} \mathrm{MoO}_{4}, 0 \cdot 03$. Apart from $\mathrm{N}$, the solution provided an adequate but not excessive nutrient supply to the young seedlings. The $\mathrm{pH}$ of the solution was maintained between 4.5 and 6.5 with daily additions of $0.1 \mathrm{M} \mathrm{KOH}$ and the solutions were changed every second day. After 3 weeks, the small number of plants that had formed nodules on their roots were discarded and the seedlings were showing the first symptoms of $\mathrm{N}$ deficiency.

Treatments. Thirty six lupin and pea seedlings were transfered to the treatments pots at a density of three plants per 5.01 pot. In the $5000 \mu \mathrm{M} \mathrm{NO}-$ treatment, $\mathrm{CaSO}_{4}$ was withheld and $\mathrm{NO}_{3}^{-}$was supplied as $\mathrm{Ca}\left(\mathrm{NO}_{3}\right)_{2}$. In the 250 , 750 and $2500 \mu \mathrm{M} \mathrm{NO}-\mathrm{NO}_{3}^{-}$treatments, ratios of $\mathrm{Ca}\left(\mathrm{NO}_{3}\right)_{2}$ and $\mathrm{CaSO}_{4}$ were supplied so that $\mathrm{Ca}^{2+}$ concentration was $2500 \mu \mathrm{M}$ in all treatments. Control pots without plants were included for each treatment. $\mathrm{pH}$ was monitored in each pot four times daily, and corrected to 5.7 with $0.01 \mathrm{~m} \mathrm{NaOH}$ or $\mathrm{HCl}$ and the level of nutrient solution in each pot was maintained by adding de-ionised water. Otherwise the solutions were left unchanged during the course of the experiment. Plants were harvested after $6 \mathrm{~d}$.

Analyses. A sample of the nutrient solution was taken from each pot and analysed for $\mathrm{K}^{+}, \mathrm{Na}^{+}, \mathrm{Ca}^{2+}$, and $\mathrm{Mg}^{2+}$ (by atomic absorption spectrophotometry) and $\mathrm{SO}_{4}^{2-}, \mathrm{NO}_{3}^{-}$and $\mathrm{H}_{2} \mathrm{PO}_{4}^{-}$(by ion chromatography) to calculate nutrient depletion by the plants. The nutrient solution was passed through a $0.45 \mu \mathrm{m}$ filter and using a Waters ${ }^{\circledR}$ ion chromatography system $100 \mu \mathrm{l}$ was injected into a Waters ${ }^{\circledR} \mathrm{HC}$ anion exchange column. The eluent was $2.5 \mathrm{~mm}$ borate/ gluconate at a flow rate of $1.5 \mathrm{ml} \mathrm{min}-1$ and ions were detected by a uv/vis spectrophotometer at $210 \mathrm{~nm}$ or by a conductivity meter. Nutrient uptake was measured in each pot from the difference in the concentration of nutrients between the control and the treatment pots. Cation-anion balance was determined from the difference between the sum of the charges of the cations and anions depleted from the nutrient solution. The excretion of $\mathrm{H}^{+} / \mathrm{OH}^{-}$by the plants was equated to the amount of $\mathrm{NaOH}$ or $\mathrm{HCl}$ required to maintain a constant $\mathrm{pH}$ during the treatment period.

The accumulation of organic anion contents was determined for the 250 and $5000 \mu \mathrm{M} \mathrm{NO} \mathrm{NO}_{3}^{-}$treatments only. Samples of the seedlings were taken for the determination of organic anion content after the pretreatment and treatment periods, so that the accumulation of organic anions could be assessed. Roots and shots were harvested separately, rinsed with de-ionised water and a 4-10 g subsample was taken. The remainder of the sample was used to measure dry weight.

The subsample was macerated in about $50 \mathrm{ml}$ of $80 \%$ ethanol, filtered through a No. 1 Whatman filter paper and was allowed to dry at room temperature for $16-32 \mathrm{~h}$. The sample was then dissolved in $20 \mathrm{ml}$ of double de-ionised water, to which about $20 \mathrm{ml}$ of petroleum ether (b.p. < $40^{\circ} \mathrm{C}$ ) was added. The sample was hand shaken and allowed to stand several times and was then placed in a freezer. When the aqueous phase had frozen the liquid ether phase containing the organic soluble components of the sample was discarded and the aqueous phase was allowed to thaw. The addition to ether, shaking and freezing the sample was repeated another two times. Using a Waters ion chromatography system, $100 \mu \mathrm{l}$ of each sample was injected into a Aminex ${ }^{\circledR}$ ion exclusion column (HPX-87H). The eluent was $2.5 \mathrm{~mm} \mathrm{H}_{3} \mathrm{PO}_{4}$ at a flow rate of $0.8 \mathrm{ml} \mathrm{min}^{-1}$ and the organic anions were detected by a uv/vis spectrophotometer at $210 \mathrm{~nm}$.

Inorganic cation-anion balance, $\mathrm{H}^{+}$excretion and organic anion accumulation were expressed per $\mathrm{g}$ dry weight per $\mathrm{d}$. The amount of organic anions excreted was estimated from the following equations. The charge of the anions and cations absorbed must equal the charge of the anions and cations excreted;

$$
A_{\text {absorbed }}-C_{\text {absorbed }}=O A_{\text {excreted }}+\mathrm{OH}_{\text {cxereted }}^{-}
$$

where $A$ and $C$ are inorganic anions and cations (other than $\mathrm{H}^{+}$or $\left.\mathrm{OH}^{-}\right)$respectively, and $O A$ is organic acid anions. Hence, organic anion excretion was calculated using;

$$
O A_{\text {excreted }}=\left(A_{\text {absorbed }}-C_{\text {absorbed }}\right)-\mathrm{OH}_{\text {excreted }}^{-}
$$

\section{Experiment 2}

The aim of this experiment was to measure the effects of three concentrations of $\mathrm{NO}_{3}^{-}(0,500$ and $2000 \mu \mathrm{M})$ on nutrient uptake, cation-anion balance, $\mathrm{H}^{+} / \mathrm{OH}^{-}$excretion and organic anion accumulation and excretion of unnodulated lupin plants. The experiment included six replicates and was conducted in a controlled growth room at $20^{\circ} \mathrm{C}$ and a $12 \mathrm{~h}$ photoperiod, during Nov. and Dec. 1991.

Seedling preparation. For expt 2, an attempt was made to prepare seedling roots in sterile conditions, because a preliminary experiment demonstrated that at the expected rate of excretion, the organic anions were decomposed within $48 \mathrm{~h}$. All equipment and nutrient solutions were autoclaved at $121^{\circ} \mathrm{C}$ for $20 \mathrm{~min}$ and were handled in a laminar flow cabinet once sterile. Seeds were surface sterilised with $12 \% \mathrm{NaOCl}$ for $4 \mathrm{~h}$, rinsed ten times with excess sterile de-ionised water and allowed to imbibe overnight in a sterile solution of $10^{-4} \mathrm{M} \mathrm{CaSO}_{4}$ and $10^{-6} \mathrm{M}$ $\mathrm{H}_{3} \mathrm{BO}_{3}$. The seeds were then immersed in a $3 \%$ solution of $\mathrm{H}_{2} \mathrm{O}_{2}$ for $10 \mathrm{~s}$, rinsed and transfered to sterile $500 \mathrm{ml}$ screw top polycarbonate vials containing sterile nutrient solution. The solution was aerated through a sterile pasteur pipette packed with cotton wool and the seeds were supported on a stainless steel mesh at a density of 20 per vial.

The composition of the nutrient solution was as in expt 1 , but also included $30 \mathrm{mg} \mathrm{l}^{-1}$ of the antibiotic cefotaxime (Kerven et al., 1991), which did not decrease lupin growth and $250 \mu \mathrm{M} \mathrm{NaNO}$. The solution was changed every second day. Preliminary tests showed that contamination was not prevented by $50 \mathrm{mg} \mathrm{ml}^{-1}$ ampicillin and $50 \mathrm{mg} \mathrm{ml}^{-1}$ strep- 
tomycin, at which concentration the growth of plants was decreased.

After 1 week, the seedling shoots were exposed to nonsterile external air through a hole in the lid of the vial, while the roots remained in the sterile nutrient solution. The seedlings were supported by sterile cotton wool around the hole in the lid with two seedlings per vial. After 3 weeks cotyledons were excised to ensure the plants were relying solely on the nutrient solution supplied. Throughout the pretreatment period, sterility was tested weekly. A small sample of nutrient solution was plated on yeast mannitol agar and examined after incubation for $48 \mathrm{~h}$ at $20^{\circ} \mathrm{C}$.

Treatments. The treatments were imposed when the plants were 4 weeks old. In the 500 and $2000 \mu \mathrm{M} \mathrm{NO}-$ treatments, $\mathrm{NO}_{3}^{-}$was supplied as $\mathrm{Ca}\left(\mathrm{NO}_{3}\right)_{2}$ and ratios of $\mathrm{Ca}\left(\mathrm{NO}_{3}\right)_{2}$ and $\mathrm{CaSO}_{4}$ were supplied so that the $\mathrm{Ca}^{2+}$ concentration was $1000 \mu \mathrm{M}$ in all treatments. The supply of $\mathrm{K}_{2} \mathrm{SO}_{4}, \mathrm{MgSO}_{4}$, $\mathrm{NaH}_{2} \mathrm{PO}_{4}$ and the micronutrients was doubled from those of the pretreatment, because the volume of nutrient solution per plant was much less than in expt 1 . Citrate $\left(100 \mu \mathrm{g}^{-1}\right)$ was also added to six pots with plants from which $\mathrm{NO}_{3}^{-}$was withheld, so that any loss from the system due to microbial decomposition could be measured. The treatment solutions were replaced after $4 \mathrm{~d}$ and again after another $4 \mathrm{~d}$ before the plants were harvested. After each treatment period, samples were collected and the nutrient solutions were titrated back to their initial $\mathrm{pH}$.

Analyses. Nutrient uptake, cation-anion balance, $\mathrm{H}^{+}$ excretion and organic anion accumulation were calculated as described as in expt 1 and expressed per g dry weight per d. The concentrations of organic anions in the nutrient solution were determined using ion chromatography as described previously, apart from the eluent, which was changed to $4 \mathrm{mM} \mathrm{H}_{2} \mathrm{SO}_{4}$ at a flow rate of $0.6 \mathrm{ml} \mathrm{min}^{-1}$.

\section{RESULTS}

\section{Experiment 1}

The growth of the seedlings during the pre-treatment phase was as expected, with the peas showing the first symptoms of $\mathbf{N}$ deficiency. These symptoms persisted throughout the treatment period for the $250 \mu \mathrm{M} \mathrm{NO}_{3}^{-}$treatment. For the other treatments there was no difference $(P<0.01)$ in the effect of the treatments on shoot or root growth for either the lupins or peas (Table 1).

Nutrient uptake and cation-anion balance. Unlike the other nutrients $\mathrm{NO}_{3}^{-}$was totally depleted in the $250 \mu \mathrm{M} \mathrm{NO}-$ treatment of both the peas and lupins, and there was a net

TABLE 1. The mean root and shoot dry weights $(\mathrm{g})$ of the various treatments and l.s.d. $(\mathrm{P}<0.0 I)$ in expt 1

\begin{tabular}{|c|c|c|c|c|c|c|}
\hline & & \multicolumn{4}{|c|}{$\mathrm{NO}_{3}^{-}$treatment $(\mu \mathrm{M})$} & \multirow[b]{2}{*}{ 1.s.d. } \\
\hline & & 250 & 750 & 2500 & 5000 & \\
\hline \multirow[t]{2}{*}{ Lupin } & Roots & 0.91 & 0.81 & 0.95 & 0.80 & $0 \cdot 16$ \\
\hline & Shoots & 1.00 & 1.02 & $1 \cdot 18$ & 1.05 & 0.21 \\
\hline \multirow[t]{2}{*}{ Pea } & Roots & $0-42$ & 0.53 & 0.56 & 0.55 & 0.12 \\
\hline & Shoots & 0.72 & 0.91 & 0.99 & $0 \cdot 86$ & 0.15 \\
\hline
\end{tabular}

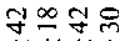
$+1+1+1+$

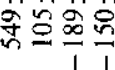

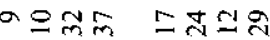

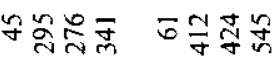

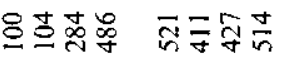

$a a \infty a \quad N= \pm$

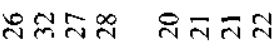

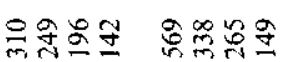

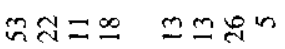

ธํำ 


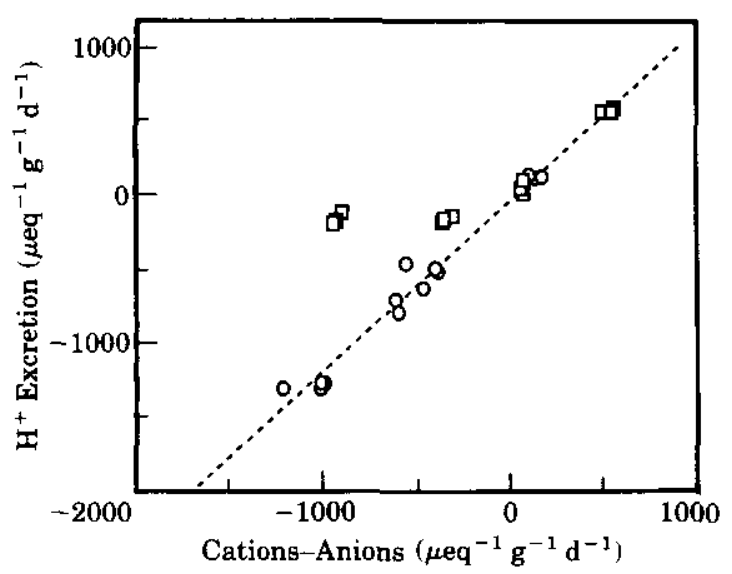

FIG. 1. The relationship between cation-anion balance and $\mathrm{H}^{+}$excretion for ( $\square$ ) lupins and (O) peas in expt 1. Individual replicates are illustrated.

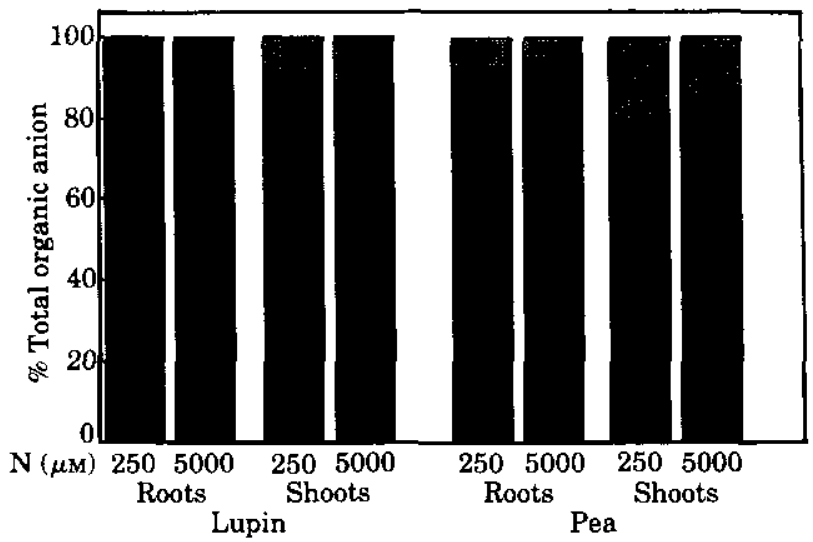

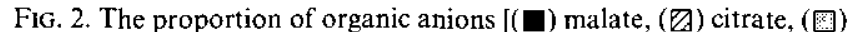
others] found in the roots and shoots of lupin and peas supplied with 250 or $5000 \mu \mathrm{M} \mathrm{NO}-$ in expt 1 .

TABLE 3. The root and shoot dry weights (g) of the treatments in expt 2. No differences were significant $(\mathrm{P}<$ 0.01 )

\begin{tabular}{lcccc}
\hline & \multicolumn{3}{c}{$\mathrm{NO}_{3}^{-}$Treatments $(\mu \mathrm{M})$} & \\
\cline { 2 - 4 } & 0 & 500 & 2000 & 1.s.d. \\
\hline Roots & 0.47 & 0.42 & 0.43 & 0.09 \\
Shoots & 0.54 & 0.50 & 0.52 & 0.14 \\
\hline
\end{tabular}

cation excess (Table 2). Apart from $\mathrm{Na}^{+}, \mathrm{Mg}^{2+}$ and $\mathrm{Cl}^{-}$, the peas absorbed more nutrients than the lupins, particularly $\mathrm{SO}_{4}^{2-}$ and $\mathrm{NO}_{3}^{-}$. These anions contributed to a trend of greater excess anion uptake with increasing $\mathrm{NO}_{3}^{-}$supply for both species, particularly the peas.

$\mathrm{H}^{+} / \mathrm{OH}^{-}$excretion. The peas increased the $\mathrm{pH}$ of the nutrient solution when supplied with greater than $250 \mu \mathrm{M}$ $\mathrm{NO}_{3}^{-}$, and there was a close linear relationship between the cation-anion balance and the amount of $\mathrm{H}^{+} / \mathrm{OH}^{-}$required to maintain a constant $\mathrm{pH}$ in the nutrient solution $\left(r^{2}=\right.$ 0.98 , Fig. 1). When the lupins absorbed an excess of anions, they excreted less than $190 \mu \mathrm{eq} \mathrm{OH}^{-} \mathrm{g}^{-1} \mathrm{~d}^{-1}$ into the nutrient medium, even when anion uptake exceeded cation uptake

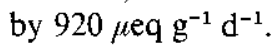

Organic anion accumulation. The total amount of organic anions accumulated by the lupins was not different $(P<$ 0.05 ) between the 250 and $5000 \mu \mathrm{M} \mathrm{NO}_{3}^{-}$treatments, with an average rate of $872 \mu \mathrm{eq} \mathrm{g}^{-1} \mathrm{~d}^{-1}$ (Table 2). About $82 \%$ of the organic anions accumulated in the roots of lupins for both $\mathrm{N}$ treatments. Peas accumulated organic acids at rates of 1235 and $395 \mu \mathrm{eq} \mathrm{g}^{-1} \mathrm{~d}^{-1}$, when supplied with 250 and $5000 \mu \mathrm{M} \mathrm{NO}-$ respectively. The proportion of the organic anions accumulated in the pea shoots was 16 and $60 \%$ when supplied with 250 and $5000 \mu \mathrm{M} \mathrm{NO}$, respectively.

The lupins accumulated mainly malate in the shoots and citrate in the roots, and there was no effect $(P<0.05)$ of the treatments on these proportions (Fig. 2). Similarly, peas accumulated mainly malate in their shoots and citrate in their roots. However more malate was present when the peas were supplied with $5000 \mu \mathrm{M}$ than $250 \mu \mathrm{M} \mathrm{NO} \mathrm{NO}_{3}^{-}$in both their shoots and roots.

Calculated organic anion excretion. The calculated excretion from lupins supplied with 250 and $750 \mu \mathrm{M} \mathrm{NO} \mathrm{Nas}_{3}^{-}$was negligible (less than $21 \mu \mathrm{eq} \mathrm{g}^{-1} \mathrm{~d}^{-1}$; Table 2). Using eqn (2), it was calculated that lupins excreted organic anions at rates of 189 and $770 \mu \mathrm{eq} \mathrm{g}^{-1} \mathrm{~d}^{-1}$ when supplied with 2500 and $5000 \mu \mathrm{M} \mathrm{NO}-$, respectively.

Peas excreted less than $101 \mu \mathrm{eq} \mathrm{g}^{-1} \mathrm{~d}^{-1}$ but because of the large standard errors, particularly with the $\mathrm{H}^{+}$excretion measurement, these quantities were not significant $(P<$ $0.05)$.

\section{Experiment 2}

The growth of the lupins during the experiments was satisfactory, and no signs of nutrient deficiencies were evident. There was no effect $(P<0.01)$ of the treatments on the root or shoot growth during the expt 2 (Table 3 ).

Sterile conditions were only maintained for about the first 3 weeks of the pretreatment period, after which contamination entered the culture system. Although contaminated, the decomposition of the organic anions was much less than in a preliminary experiment. An average of $42 \mu \mathrm{g} \mathrm{m}^{-1}$ of the $100 \mu \mathrm{g} \mathrm{ml}^{-1}$ citrate added to the vials was recovered after the $4 \mathrm{~d}$ treatment periods, a decomposition rate of $0.6 \mu \mathrm{g} \mathrm{ml}^{-1} \mathrm{~h}^{-1}$. This was about one tenth of the decomposition rate measured in a preliminary experiment where lupins were grown in a non-sterile culture system, similar to expt 1 .

No significant $(P<0.05)$ quantities of organic acids were detected after the first $4 \mathrm{~d}$ collection period and only results from the second collection period are presented and discussed.

Cation-anion balance and $\mathrm{H}^{+} / \mathrm{OH}^{-}$excretion. The uptake of nutrients in expt 2 was at similar rates to those in expt 1 . There was no difference $(P<0.05)$ between the excess cation uptake and $\mathrm{H}^{+}$excreted by lupin roots which were not supplied with $\mathrm{NO}_{3}^{-}$(Table 4). When supplied with $\mathrm{NO}_{3}^{-}$, lupins absorbed more $\mathrm{Ca}^{2+}$ and $\mathrm{K}^{+}$and less $\mathrm{SO}_{4}^{2-}$ than when not supplied with $\mathrm{NO}_{3}^{-}$; however, the uptake of $\mathrm{NO}_{3}^{-}$ counteracted these effects and an excess of anion uptake resulted. Despite the excess of anion uptake, the lupins 
supplied with $\mathrm{NO}_{3}^{-}$excreted small quantities of $\mathrm{OH}^{-}$(less than $50 \mu \mathrm{eq} g \operatorname{root}^{-1}$ ).

Organic acid anion accumulation. Unlike expt 1 , there was a trend for the lupins to accumulate less organic anions with increasing $\mathrm{NO}_{3}^{-}$supply (Table 4 ). The proportions and types of organic anions accumulated in the roots and shoots were not affected by the $\mathrm{NO}_{3}^{-}$supply. An average of $86 \%$ of the organic anions in the plant were in the roots, of which $81 \%$ was citrate.

Organic acid anion excretion. Of the organic anions excreted, $98 \%$ was citrate with the remainder being malate. Lupins excreted up to $87 \mu \mathrm{eq} \mathrm{g}^{-1} \mathrm{~d}^{-1}$ organic anions and there was a strong trend of increasing organic anion excretion with increasing excess of anion uptake and $\mathrm{NO}_{3}^{-}$ uptake (Table 4). Despite the microbial contamination, there was close agreement between the organic anion excretion calculated from the model and that estimated by direct measurements $\left(r^{2}=0.85\right)$.

\section{DISCUSSION}

Lupins and peas have different mechanisms of maintaining internal charge balance when supplied with $\mathrm{NO}_{3}^{-}$and a different metabolism of organic acid anions. Lupins absorbed less $\mathrm{NO}_{3}^{-}$than peas on a dry weight basis at the same $\mathrm{NO}_{3}^{-}$supply, which largely accounted for the smaller excess of inorganic anion uptake over inorganic cation uptake in lupins than in peas. When inorganic anion uptake exceeded inorganic cation uptake, lupins excreted an equivalent negative charge as citrate and a small amount of $\mathrm{OH}^{-}$. In expt 1 , peas excreted $\mathrm{OH}^{-}$in amounts equivalent to their excess of inorganic anion over inorganic cation uptake, and no significant quantity of organic anion excretion was calculated.

The majority of the organic anions accumulated in the roots of the lupin and in the shoots of peas, which relates to the proportion of $\mathrm{NO}_{3}^{-}$reduction in the roots and shoots for both species when supplied with moderate concentrations of $\mathrm{NO}_{3}^{-}$(Andrews et al., 1984). Sulphate reduction is widely spread throughout the organs of higher plants (Schiff, 1983 ), and is proportionally smaller than $\mathrm{NO}_{3}^{-}$reduction. Hence, $\mathrm{SO}_{4}^{2-}$ reduction may have little effect on the distribution of organic anion accumulation. Van Beusichem et al. (1985) showed that $80 \%$ of the $\mathrm{NO}_{3}^{-}$and $\mathrm{SO}_{4}^{2-}$ reduction and a large proportion of organic anion accumulation was located in the shoots of castor oil plants.

Why lupins should excrete citrate rather than $\mathrm{OH}^{-}$is not clear. Organic anions may increase the availability of some nutrients. Gardner, Parbery and Barber (1982) and Dinkelaker, Römheld and Marschner (1989) measured exudates from the proteoid roots of $\mathbf{P}$ and $\mathbf{F e}$ deficient white lupins ( $L$. albus L.) in soil. They noted that the exudates were

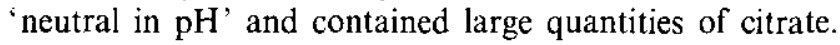
While the narrow-leaved lupins used in this study do not form proteoid roots and did not show signs of $\mathbf{P}$ or $\mathrm{Fe}$ deficiency, organic anion excretion occurred. Unlike peas, the root growth of $L$. angustifolius $\mathrm{L}$. is decreased by increasing the solution $\mathrm{pH}$ from 5.5 to 6.0 (Tang et al., 1992), and the excretion of organic anions rather than $\mathrm{OH}^{-}$ when inorganic anion uptake exceeds inorganic cation 
uptake is perhaps a method of preventing high $\mathrm{pH}$ in the rhizosphere.

The excretion of citrate by lupins may explain their relatively high acid and aluminium tolerance, because citrate is a strong chelator capable of detoxifying $\mathrm{Al}^{3+}$. Christiansen-Weniger, Gronemen and Van Veen (1992) demonstrated that the aluminium tolerance of wheat cultivars was closely related to the amount of organic anion excretion from their roots.

Growing seedling roots in sterile conditions was not achieved despite the measures taken in this study. Kerven et al. (1991) also did not achieve complete sterility when plants were grown in $30 \mathrm{mg}^{-1}$ cefotaxime, however they did not measure any significant loss of organic acids from their system due to microbial decomposition. It might be expected that the micro-organisms will break down the organic anions to $\mathrm{OH}^{-}$and $\mathrm{CO}_{2}$, however there was no increase in the $\mathrm{pH}$ of the nutrient solution in these and other experiments (Atwell, 1992; Loss et al., 1993b). Microorganisms may convert the organic anions into microbial biomass containing carboxylate groups that do not affect the $\mathrm{pH}$ of the external nutrient solution. It is not known if this would also occur in soil.

These results have implications for subsoil acidification under lupins in the mediterranean-type climate of Western Australia and elsewhere. The cultivation of lupins for grain (L. angustifolius L.) causes increased soil acidification, particularly in the subsoil where more shallow rooted legumes have little effect on soil pH (Coventry and Slattery, 1991; Loss, Ritchie and Robson, 1993a). In a previous study (Loss et al., 1993b), nodulated lupins were grown in a vertical split pot which allowed the upper and lower zones of roots to be supplied with varying concentrations of $\mathrm{K}^{+}$ and $\mathrm{NO}_{3}^{-}$. Proton excretion was not distributed evenly over the entire root length but was concentrated in zones of high cation uptake, and hence differences in nutrient uptake by roots between the surface soil and the subsoil will lead to different rates of $\mathrm{H}^{+}$excretion.

Nitrate is rapidly leached in the coarse sandy soils to which lupins are best adapted in Western Australia (Diggle, Bowden and D'Antuono, 1990) and up to $10 \mathrm{~mm} \mathrm{NO}_{3}^{-}$has been measured in the soil solution extracted from a sandy subsoil (Carr, pers. comm.). Although lupins are reputed to have a low capacity to absorb $\mathrm{NO}_{3}^{-}$, they may absorb significant quantities from the subsoil with the onset of the summer drought when the soil nearer the surface begins to dry. Previous results (Loss et al., 1993b) indicate that plants maintain their electroneutrality at the site of nutrient uptake and the excess anion uptake in the subsoil roots would result in the excretion of citrate in the subsoil. Provided the $\mathrm{pH}$ of the soil is greater than $5 \cdot 4$, the $\mathrm{pKa}_{2}$ value of citrate, most of the excreted citrate would remain as an anion and would not affect the soil $\mathrm{pH}$. Combined with cation uptake, particularly $\mathrm{K}^{+}$, this mechanism could lead to considerably more subsoil acidification under lupins than under other plant species, as was measured in the field (Loss et al., $1993 a)$.

\section{ACKNOWLEDGEMENTS}

We gratefully acknowledge financial support provided by the Soil Fertility Trust Fund of W.A. and the W.A. Committee of the Grains Research and Development Corporation.

\section{LITERATURE CITED}

Andrews M, Sutherland JM, Thomas RK, Sprent JI. 1984. Distribution of nitrate reductase activity in six legumes: The importance of the stem. New Phytologist 98: 301-310.

Atwell BK. 1992. Nitrate and ammonium as nitrogen sources for lupins prior to nodulation. Plant and Soil 139: 247-251.

Christiansen-Weniger C, Gronemen AF, Van Veen JA. 1992. Associative $\mathrm{N}_{2}$ fixation and root exudation of organic acids from wheat cultivars of different aluminium tolerance. Plant and Soil 139: $167-174$.

Coventry DR, Slattery WJ. 1991. Acidification of soil associated with lupins grown in a crop rotation in north-eastern Victoria. Australian Journal of Agricultural Research 42: 391-397.

Davies DD. 1973. Control of and by pH. Symposium of the Society of Experimental Biology 27: 513-530.

Diggle AJ, Bowden JW, D'Antuono M. 1990. A comparison of the effects of mineral and organic nitrogen sources on the distribution of wheat roots in a leaching environment. Australian Journal of Soil Research 28: 963-971.

Dinkelaker B, Römheld V, Marschner H. 1989. Citric acid excretion and precipitation of calcium citrate in the rhizosphere of white lupin (Lupinus albus L.). Plant, Cell and Environment 12: 285-292.

Gardner WK, Parbery DG, Barber DA. 1982. The acquisition of phosphorus by Lupinus albus L. I. Some characteristics of the soil/root interface. Plant and Soil 68: 19-32.

Jarvis SC, Robson AD. 1983. The effects of nitrogen nutrition of plants on the development of acidity in Western Australian soils. II. Effects of differences in cation/anion balance between plant species grown under non-leaching conditions. Australian Journal of Agricultural Research 34: 355-365.

Kerven GL, Asher CJ, Edwards DG, Ostatek-Boczynski Z. 1991. Sterile solution culture techniques for aluminium toxicity studies involving organic acids. Journal of Plant Nutrition 14: 975-985.

Loss SP, Ritchie GSP, Robson AD. 1993a. The effect of lupins on soil acidification and fertility in Western Australia. Australian Journal of Experimental Agriculture 33: 457-464.

Loss SP, Robson AD, Ritchie GSP. 1993b. Nutrient uptake and $\mathrm{H}^{+} / \mathrm{OH}^{-}$excretion in upper and lower parts of lupin ( $L$. angustifolius L.) root systems. Annals of Botany 72: 315-320.

Schiff JA. 1983. Reduction and other metabolic reactions of sulfate. In: Laüchli A, Bieleski RL, eds. Encyclopedia of plant physiology 15 A-Inorganic plant nutrition. Berlin: Springer-Verlag, 35-42.

Tang C, Longnecker NE, Thomson CJ, Greenway H, Robson AD. 1992. Lupin (Lupinus angustifolius L.) and pea (Pisum sativum L.) roots differ in their sensitivity to $\mathrm{pH}$ above 6.0. Journal of Plant Physiology 140: 715-719.

Van Beusichem ML. 1981. Nutrient absorption by pea plants during dinitrogen fixation I. Comparison with nitrate nutrition. Netherlands Journal of Agriculture 29: 259-272.

Van Beusichem ML, Baas R, Kirkby EA, Nelemans JA. 1985. Intracellular $\mathrm{pH}$ regulation during $\mathrm{NO}_{3}^{-}$assimilation in shoot and roots of Ricinus communis. Plant Physiology 78: 768-773.

Van Beusichem ML, Kirkby EA, Baas R. 1988. Influence of nitrate and ammonium nutrition on the uptake, assimilation, and distribution of nutrients in Ricinus communis. Plant Physiology 86: 914-921. 